\title{
Etnografía dentro y fuera de los estudios migratorios: una revisión pertinente
}

\author{
Laura Calle Alzate \\ Profesora PhD de la Universidad Complutense de Madrid, España \\ Icalle@ucm.es \\ María del Carmen Villarreal Villamar \\ Postdoctoranda en la Universidade Estadual do Norte Fluminense, Brasil \\ mariavillarreal85@gmail.com
}

Resumen Este artículo pretende dar cuenta de los usos, retos y oportunidades brindadas por la etnografia en los estudios migratorios y otros campos de investigación. Con este fin, ofreceremos, en primer lugar, un breve resumen sobre la historia del trabajo de campo etnográfico y una descripción y análisis de la etnografia en cuanto método, texto y enfoque. A seguir, nos detendremos en el análisis de la etnografia en los estudios migratorios, partiendo de las etnografias clásicas hasta el desarrollo de las etnografias multisituadas. Finalmente, daremos cuenta de la diversidad de campos de aplicación de la etnografia y de sus raíces interdisciplinares y multitécnicas. A su vez, en consonancia con los cambios propiciados por la globalización y la difusión de las nuevas Tecnologías de la Información y Comunicación (TICs) abordaremos también las potencialidades y límites de la etnografia de la cibercultura o etnografia digital.

Palabras clave: Etnografia, migraciones internacionales, diásporas, etnografia digital.

\section{Introducción}

En la primera mitad del siglo XX, el trabajo de campo etnográfico se centró en la relación ente el etnógrafo y el los denominados "nativos". Esta relación se reformuló con los movimientos de liberación y la caída del colonialismo (Asad, 1979; Nash, 1975). Se habló entonces de la fragmentación de la mirada antropológica. Además, con la publicación de $A$ Diary in the Strict Sense of the Term de Malinowski en 1967, después de un cuarto 
de siglo de su fallecimiento, se generó un gran revuelo sobre lo que había detrás de la etnografía.

Como muchos conocerán, esta última era una edición de las notas de campo que el antropólogo polaco había realizado en Nueva Guinea y las islas Trobriand, en los períodos 1914-1915 y 1917-1919, como señalaremos más adelante. El diario mostraba un Malinowski diferente al que la antropología había mitificado como "héroe cultural", pues visibilizaba las características humanas del etnógrafo, sin ese supuesto respeto aséptico por el "nativo". Esta nueva imagen distaba mucho de la del "héroe cultural" objetivo y científico que registraba imparcialmente las cualidades de las diferentes culturas y las analizaba con la misma ausencia de pasión.

Esto causó una gran agitación entre algunos antropólogos, no solo por cuestionar el buen nombre de uno de los precursores de la disciplina, sino además por poner en tela de juicio el propio método etnográfico. También generó fuertes debates metodológicos pues quebró la seguridad epistemológica de la disciplina y cuestionó la autoridad etnográfica (Geertz, 1989; Apud, 2013). El diario íntimo de Malinowski reveló, como anotó Clifford (1985) que, las mejores ficciones etnográficas son, como la de Malinowski, intrincadamente veraces; pero sus hechos, son clasificados, contextualizados, narrados e intensificados. No es insólito que veinte años después de su publicación y paralelo al llamado "giro posmodeno" el diario fuese considerado por Geertz (1989) como la "doble hélice" de la antropología moderna, pues el texto indicaba que la queja metodológica y epistemológica planteada en los años ochenta ya estaba presente en el origen mismo de la antropología.

De acuerdo con Apud (2013), este quiebre tuvo como correlato positivo la visibilización de las contradicciones y conflictos que solía tener el etnógrafo "[...] abriendo un campo de reflexión desidealizado del antropólogo como investigador, y asentando el tema de la reflexividad, la implicación y la problematización de la escritura antropológica [...]" (p. 223). Esto llevó a la reflexión y experimentación de nuevos tipos de escritura etnográfica, pues el diario de Malinowski inició una conciencia reflexiva sobre la necesidad de un tipo de escritura más honesta y que diera cuenta tanto de las complejidades como de las contradicciones que el etnógrafo experimentaba en el campo (Clifford, 2001; Apud 2013). Así, Clifford (1985), se refirió al texto etnográfico como texto polifónico y heteroglósico.

Los debates sobre la etnografia no han cesado desde entonces. En nuestra opinión, la etnografia, a pesar de ser una concepción y práctica de conocimiento diseñada hace un siglo, sigue estado vigente y se ha transformado y redefinido en el tiempo. Así, el presente artículo surge como una iniciativa de diálogo interdisciplinar sobre la etnografia y sus nuevos usos.Ambas autoras hemos utilizado la etnografia en varios estudios; desde diferentes disciplinas, - la ciencia política y la antropología. A pesar de las diferencias disciplinares y de enfoque, consideramos que la etnografía no está en desuso, por el contrario, pensamos que sigue estando vigente, por lo que nos hemos aventurado a plasmar en este texto una versión breve de su evolución hasta el día de hoy, el giro que experimenta con el estudio de las migraciones y la sociedad transnacional, para luego hablar de las etnografias digitales 
y los nuevos usos que podemos darle. De esta forma, el artículo está dividido en cuatro partes. Una primera en la que hacemos un resumen sucinto sobre la historia del trabajo de campo etnográfico. Enseguida comentaremos sobre la triple acepción de la etnografia como método, texto y enfoque, para luego profundizar en el análisis de la etnografía en los estudios migratorios. Por último, daremos cuenta de la diversidad de campos de aplicación de la etnografia y de sus raíces interdisciplinares y multitécnicas. De acuerdo con los cambios propiciados por la globalización y la difusión de las nuevas Tecnologías de la Información y Comunicación (TICs) abordaremos también las potencialidades y límites de la etnografia digital.

\section{Etnografía: Orígenes y características}

Etimológicamente se suele definir la etnografia como la "descripción de un pueblo", por eso, debemos entender que la etnografia se ocupa de las personas en sentido colectivo, no de los individuos. Así, es una manera de estudiar a las personas en grupos organizados y duraderos a los que cabe referirse como comunidades o sociedades. El modo de vida distintivo que caracteriza a un grupo de esta índole es su cultura (Angrosino, 2012) y el estudio de la cultura implica un examen del comportamiento, las costumbres y las creencias que aprenden y comparten los miembros del grupo.

Restrepo (2016) asevera que "[...] la etnografia se puede definir como la descripción de lo que una gente hace desde la perspectiva de la misma gente [...]" (p. 16). Por lo tanto, como señala Guber (2001), “[...] la etnografia es una concepción y práctica de conocimiento que busca comprender los fenómenos sociales desde la perspectiva de sus miembros [...]" (p.12). A los etnógrafos y etnógrafas nos interesa, por lo tanto, lo que la gente hace, es decir, sus prácticas, pero también los significados que estas adquieren para la gente. En esta línea, los estudios etnográficos buscan describir contextualmente la compleja relación que existe entre las prácticas sociales y los significados que le otorgan los agentes a las mismas. Esto último con el fin de describir "lo que la gente hace" y "lo que la gente dice que hace" para comprender la complejidad de la vida social del grupo, pueblo o colectivo que estemos estudiando (Restrepo, 2016). Debido a que la etnografia busca una descripción detallada y amplia de un pueblo, la realizan habitualmente investigadores que pueden pasar un tiempo prolongado en la comunidad que están estudiando, realizando lo que comúnmente denominamos trabajo de campo etnográfico (Angrosino, 2012).

Históricamente se ha asociado a la etnografia con las investigaciones que suelen hacer los antropólogos. Inclusive, en algunos manuales de antropología se define la etnografia como "[...] la estrategia distintiva de la antropología [...]" (Kottak, 2011), por lo que en muchos casos se piensa que esta solo puede ser practicada por aquellos investigadores que se desplazan por largos periodos de tiempo a zonas alejadas para conocer los diversos aspectos de la cultura de una sociedad. Lo cierto es que tanto la antropología como la etnografia se han transformado en el tiempo (Ortner, 1984) y en la actualidad no solo es utilizada por 
antropólogos preocupados por comprender las sociedades preindustriales. Por lo tanto, aunque la investigación etnográfica se inició con los antropólogos a finales del siglo XIX y principios del XX, ha formado parte desde entonces de la caja de herramientas de los investigadores, sobre todo cualitativos, en muchas disciplinas (Angrosino, 2012).

Como bien señala Restrepo (2016), desde hace varias décadas, profesionales de otras ciencias sociales como la economía, sociología y la ciencia política, entre otras, acuden a la etnografia para desarrollar sus investigaciones. Consecuentemente, no podemos decir que la etnografia sea algo exclusivo de los antropólogos hoy en día, pero sí que fue gracias a la disciplina antropológica que surgió y se desarrolló. Tradicionalmente, un investigador o investigadora debía tener una experiencia de campo en otra sociedad para convertirse en antropólogo, algo así como un "rito de paso". Fue así como los primeros etnógrafos convivieron con comunidades, relativamente aisladas o "exóticas", con tecnologías y economías no industrializadas. La etnografía surgió como una estrategia metodológica para investigar aquellas sociedades consideradas como homogéneas e igualitarias, a diferencia de las que prevalecían en los países industrializados (Kuper, 1973; Kottak, 2011).

Con el fin de comprender una cultura particular como un todo, los etnógrafos se mueven libremente entre diversos escenarios, lugares y sujetos para recabar información y descubrir la totalidad y la interconexión de la vida social de la comunidad estudiada. La etnografia nos proporciona bases para establecer ciertas generalizaciones y teorizaciones acerca del comportamiento humano y de la vida social que trascienden los sitios y gentes con los que se realizó el estudio etnográfico (Kottak, 2011; Restrepo, 2016). Para Restrepo, este es un punto primordial para el etnógrafo, pues debe tener la capacidad de resaltar las singularidades de un contexto, al tiempo que establece la forma en que esas singularidades aportan a la compresión y conceptualización de lo que sucede en otros escenarios. Por ejemplo, un estudio etnográfico sobre los trayectos migratorios del pueblo yaqui entre México y los Estados Unidos, nos puede ofrecer elementos para comprender y teorizar otro tipo de procesos migratorios como el de los marroquíes a España. Por consiguiente, la etnografia implica una comprensión contextual y detallada de un escenario para establecer conexiones y conceptualizaciones que lo vinculan con otros más generales (Restrepo, 2016).

\section{Una breve mirada al pasado}

A finales del siglo XIX la antropología se formalizó como disciplina científica. La revolución industrial generó profundas transformaciones en las sociedades europeas y los científicos sociales se vieron en la necesidad de explicarlas. De manera paralela tuvo lugar la expansión colonial de Occidente sobre otros pueblos, culturas y territorios, dando paso a nuevos encuentros interculturales. Estos últimos despertaron una actitud de extrañeza hacia pueblos y culturas diferentes a la europea, pero, a diferencia de encuentros anteriores, como en el caso de la colonización de América, estos pueblos y culturas 
se constituyeron en objetos de investigación (Boivin; Rosato; Arribas, 2004). Fue así como los primeros etnólogos buscaron, en el hilo común de la historia de la humanidad, organizar la información dispersa sobre aquellas culturas exóticas que les llegaban a través de comerciantes, misioneros y funcionarios coloniales (Guber, 2001). Estos etnólogos tenían la idea de que aquellos pueblos permanecían en su forma "tradicional", es decir, que permanecían anclados en el pasado y, consecuentemente, podían dar claves para entender cómo habían sido las sociedades occidentales.

Sin embargo, el estudio de grupos humanos desde una perspectiva etnográfica comenzó con aquellos antropólogos que se convencieron de que las especulaciones filosóficas "de sillón"1 no eran suficientes para comprender el modo en que vivía una sociedad. Esto coincide con la crisis del evolucionismo como paradigma y la emergencia del estructuralismo y funcionalismo británico, por una parte, y el particularismo histórico estadounidense, por otra. Una de las críticas que estas nuevas corrientes hacen al evolucionismo es justamente a las técnicas y métodos utilizados para obtener información sobre estas sociedades. Como señalamos anteriormente, los evolucionistas habían construido sus teorías sobre datos que habían sido obtenidos, en su mayoría, por "terceros". Estos datos no podían ser verificados y tampoco eran coherentes. Según algunos antropólogos, esto llevó a los evolucionistas a cometer el error de construir una versión deformada de la realidad, pues los datos eran recolectados por personas sin formación académica y con prejuicios (Ver Malinowski, [1922] 2001, p. 44-45).

Discutieron entonces, que los datos debían ser obtenidos de primera mano y que el etnólogo debía ser el encargado de buscar en esas otras sociedades los datos que le permitirían construir teorías (Boivin; Rosato;Arribas, 2004). Así, llegaron a la conclusión de que solo a través del trabajo de campo in situ se podría obtener información fehaciente sobre las costumbres de las sociedades estudiadas. Como resultado, los antropólogos desarrollaron una forma de investigación etnográfica o trabajo de campo, la observación participante. Esta implicaba el traslado del etnógrafo a otras sociedades.

Dos de los protagonistas de esta nueva etapa son Franz Boas y Bronisłav Malonowski, considerados los precursores principales del trabajo de campo (Bulmer, 1982; Urry, 1984; Guber, 2001; Boivin; Rosato; Arribas, 2004). Boas sostenía la necesidad de realizar un trabajo intensivo y en profundidad en unas pocas comunidades con el fin de producir material etnográfico que diera cuenta de la manera en que pensaban, hablaban y actuaban las gentes estudiadas en sus propios términos, es decir, el etnógrafo buscaba el "punto de vista del nativo", y se apoyaba en la gente local para explicar las cosas y decir si algo es significativo o no. El naturalista alemán, estaba interesado en el estudio de pueblos nativos americanos que, para entonces, habían experimentado tanto el etnocidio como el genocidio, por lo que su trabajo, y el de otros antropólogos de la academia estadounidense, se fundamentó en la reconstrucción del pasado de esos pueblos por medio de historias orales. Boas acostumbraba permanecer temporadas breves con los "nativos" y su trabajo

1 Nos referimos a los armchair antrhropologists o “antropólogos de sillón”. 
de campo se apoyada fundamentalmente en un informante clave. Este último se refiere a aquel individuo que le enseña al etnógrafo acerca de su cultura y que proporciona la perspectiva emic, es decir, las explicaciones y significados locales.

Del otro lado del océano, Malinowski realizó un trabajo de campo pionero y es considerado el padre de la etnografía en virtud de sus años de trabajo de campo en las islas Trobriand. En la clásica obra Los Argonautas del Pacifico Occidental ([1922] 2001) Malinowski no solo describió una práctica como el kula, adoptando, en la medida de lo posible, el punto de vista de los nativos. En la introducción de esta obra responde a una serie de cuestionamientos disciplinarios, por lo que este texto/trabajo se considera la piedra fundacional del método etnográfico (Guber, 2001). Allí el autor enumeró tres principios metodológicos para realizar un trabajo de campo:

[...] ante todo, el estudioso debe albergar propósitos estrictamente científicos y conocer las normas y los criterios de la etnografía moderna. En segundo lugar, debe colocarse en buenas condiciones para su trabajo, es decir, lo más importante de todo, no vivir con otros blancos, sino entre los indígenas. Por último, tiene que utilizar cierto número de métodos precisos en orden a recoger, manejar y establecer sus pruebas [...] (Malinowski, [1922] 2001, p. 45-46).

Malinowski creía que todas las costumbres e instituciones en la sociedad estaban integradas e interrelacionadas, por tanto, proponía un conocimiento holístico de la cultura. Así lo manifiesta en la introducción de los Argonautas: "[...] un trabajo etnográfico riguroso exige, sin duda, tratar con la totalidad de los aspectos sociales, culturales y psicológicos de la comunidad, pues hasta tal punto están entrelazados que es imposible comprender uno de ellos sin tener en consideración todos los demás [...]" (Malinowski, [1922] 2001, p. 29).

Guber (2001, p. 34) señala que, para la década de los treinta, el trabajo de campo prolongado y especializado en el estudio de una cultura ya constituía una práctica habitual para los antropólogos. Posteriormente, la etnografia se desarrollaría a partir de los trabajos de la Escuela de Sociología de Chicago - cuyos pormenores serán profundizados en próximos apartados -, así como mediante las reflexiones acerca del rol de los etnógrafos como seres socioculturales con un saber históricamente situado (Guber, 2001) y como sujetos que se transforman en su ejercicio, mediante la desnaturalización de sus concepciones culturales (Restrepo, 2016), el cuestionamiento del etnocentrismo y el desarrollo de un mayor relativismo cultural. Como ya señalamos en la introducción, la publicación de los diarios de Malinowski en los años sesenta y la constatación de las brechas existentes entre discursos y principios, por un lado, y prácticas, por otro, habrían de promover también profundas críticas en relación a la figura del etnógrafo y el quehacer etnográfico. 


\section{La triple acepción}

Según Agar (1980), la etnografia debe percibirse desde dos dimensiones, pues es a la vez un método de investigación y un producto de esa investigación (Agar, 1980 apud Angrosino, 2012). La primera dimensión, asociada a la etnografía como método, se relaciona con la manera en que se recolectan los datos y a las técnicas utilizadas para tal fin. La segunda, la etnografía como producto, es un informe que incorpora la información recogida por el método etnográfico en una descripción integral de la cultura de la comunidad (Angrosino, 2012). Por su parte, Guber (2011) y Restrepo (2016) añaden una tercera dimensión, la del enfoque o encuadre metodológico. A continuación, pasaremos a describir estas tres dimensiones o acepciones de la etnografía.

Empecemos con el enfoque, que tiene que ver con la etnografia como práctica de conocimiento que busca entender los fenómenos sociales "[...] desde la perspectiva de sus propios miembros (entendidos como "actores", "agentes", "sujetos sociales") [...]" (Guber, 2001, p. 12). La descripción de lo que un grupo humano hace desde la perspectiva del propio grupo expone determinados aspectos de la vida social considerando los significados inscritos por los propios agentes. Por lo tanto, como señala Guber (2001), los interlocutores o sujetos de investigación del etnógrafo, son informantes privilegiados, pues solo ellos pueden dar cuenta de lo que piensan, sienten, dicen y hacen con respecto a los acontecimientos sociales en los que están involucrados. Para realizar un estudio con enfoque etnográfico, es imprescindible aplicar un método particular de investigación y esto nos lleva a la segunda acepción: la etnografia como método.

"[...] La etnografia es el conjunto de actividades que se suele designar como "trabajo de campo", y cuyo resultado se emplea como evidencia para la descripción [...]" (Guber, 2001, p. 16). Dentro de estas actividades podemos resaltar una serie de técnicas y herramientas como la observación participante, la residencia prolongada con los sujetos de estudio, las entrevistas, el método genealógico, las historias de vida, entre otros. En particular, la observación participante es primordial, pues el etnógrafo participa de la vida cotidiana de la sociedad o grupo con el que trabaja y, desde su propia experiencia y la observación directa, conoce de primera mano lo que está estudiando (Restrepo, 2016). Como personas que vivimos y participamos de los procesos comunitarios, no podemos ser observadores totalmente imparciales y desconectados. Por lo tanto, la etnografía es un oficio que solo se aprende desde la práctica misma, pues la formación de la sensibilidad y perspectiva etnográfica es algo que solo ocurre "haciendo etnografia"; el etnógrafo es el dispositivo de producción de conocimiento, por lo que las sensibilidades, habilidades y limitaciones del etnógrafo median la etnografia (Restrepo, 2016).

Finalmente, hablaremos de la etnografia como texto (Marcus; Cushman, 1982; Guber, 2001) o como tipo de escritura ${ }^{2}$ (Restrepo, 2016) y que podemos asociar a la segunda dimensión presentada por Agar (1980) de la etnografía como producto. Después de la década 
de los ochenta, la escritura etnográfica y las notas de campo comenzaron a ocupar un lugar importante en la Antropología (Lederman, 1990; Clifford; Marcus, 1986; Marcus; Cushman, 1982; Emerson; Fretz; Shaw, 1995; Guber, 2004). Nos referimos entonces a la descripción del comportamiento en una cultura o grupo humano en particular que resulta del trabajo de campo etnográfico. Esta descripción puede ser un libro, informe, artículo, las notas del diario de campo e inclusive un audiovisual donde el o la etnógrafa, no solo representa e interpreta, sino que traduce determinados aspectos de vida de ese grupo humano para un público que no esté familiarizado con este.

Por lo general,los registros escritos elaborados por los etnógrafos/as durante su trabajo de campo han sido considerados anexos secundarios dentro del proceso de investigación, aunque siempre se haya reconocido que llevar un diario es todavía la actividad central del trabajo de campo (Guber, 2004). Este viraje teórico y metodológico puso sobre la mesa la acepción de la etnografía como texto.

Existe entonces una compleja articulación entre el trabajo de campo, los materiales escritos que se producen mientras se realiza y el producto final. Consecuentemente, como señala Restrepo (2016), el o la etnógrafa debe desarrollar la habilidad de contar, pues "[...] la labor etnográfica requiere de un registro escrito constante y sistemático de aquello que el etnógrafo ha observado o experimentado [...]" (p. 22). Asimismo, el etnógrafo/a debe ser un buen escritor, pues la redacción de un texto etnográfico implica poner en palabras o imágenes, en el caso audiovisual, los resultados de las observaciones e interpretaciones sobre lo estudiado, relatando así aspectos verídicos que provienen de una investigación empírica y rigurosa (Restrepo, 2016).

A este respecto, la etnografia produce un conocimiento situado que, sin embargo, no está vinculado a un territorio, tiempo o lugar fisico determinado, sino que, como veremos a seguir, - especialmente cuando se trata de migrantes y otros sujetos móviles o en el estudio de comunidades virtuales - puede ser realizada de forma simultánea en diversos puntos o contextos trasnacionales e incluso en el ciberespacio. En sintonía con los nuevos tiempos, nuevas tecnologías y nuevas modalidades de interacción, la etnografía asume, entonces, nuevos rasgos y nuevas potencialidades.

\section{La etnografía en los estudios migratorios: de la etnografía clásica a la etnografía transnacional}

El interés por el "otro" y lo "otro", al igual que la voluntad de estudiar sobre el terreno las particularidades del fenómeno migratorio y sus consecuencias - dentro y fuera de las fronteras nacionales -, ha sido objeto de interés de diversas disciplinas y, especialmente, de la sociología y la antropología. La primera, tiene como antecedentes los trabajos realizados a finales del siglo XIX y comienzos del siglo XX por autores europeos como Charles Booth, Frédéric Le Play y Herbert Spencer (Fernández-Kelly, 2013, p. 496) o las aportaciones sobre grupos y relaciones étnicas (Weber, [1922], 2002). No obstante, 
es con investigaciones como The Polish Peasant in Europe and America ${ }^{3}$ o The Guetto, que surge la sociología de las migraciones, adquiriendo una base empírica, fundamentada en la observación y el trabajo de campo.

Ambas obras, al igual que otros trabajos de la Escuela de Chicago, bajo la dirección de Robert Park $^{4}$, se caracterizaban por adoptar una perspectiva interdisciplinar ${ }^{5}$ y tenían por objetivo comprender procesos comola movilidad humana,la organización/desorganización social, la aculturación, la asimilación, las relaciones étnicas y las condiciones de vida de individuos o grupos en la ciudad de Chicago. Dichos procesos eran estudiados en el marco de macrofenómenos como la industrialización, la urbanización y la modernidad. Aquí, el "otro" y lo "otro" eran representados por el negro y el extranjero, mientras que Chicago era el "laboratorio social por excelencia", ya que constituía un escenario privilegiado de observación, registrando inmigración transatlántica, por un lado, y, por otro, migración interna y de población afroamericana procedente del sur de Estados Unidos (Ribas, 2004, p. 27).

A nivel antropológico, los estudios migratorios surgen a partir de la primera mitad del siglo XX, de la mano de la antropología social y africanista británica. En este contexto, amén de trabajos precursores como el de Audrey Isabel Richards (1939), las investigaciones más sobresalientes fueron las de la Escuela de Manchester acerca de la migración y urbanización en África subsahariana. Su agenda de investigación tuvo como objetos de estudio el cambio social, las transformaciones urbanas y los impactos en los estilos de vida tras procesos migratorios rurales-urbanos de carácter interno e internacional. Guiados por Max Gluckman, los exponentes de esta escuela como Victor Turner o Clyde Mitchell, realizaron importantes contribuciones teóricas y prácticas en relación a la etnografía, especialmente en lo que concierne el método del caso ampliado y análisis situacional (Evens; Handelman, 2006, p. 7). Tras los trabajos pioneros realizados en África, se llevaron a cabo también numerosas investigaciones sobre la movilidad ruralurbana en América Latina, Irlanda y Europa del Sur. En su conjunto estas investigaciones anticiparon concepciones desarrolladas posteriormente en los estudios migratorios respecto a las redes sociales y a las etnografías bipolares o multisituadas (Giménez, 2007).

Desde los años setenta la atención de la etnografía sobre migraciones se desplazó hacia el retorno en contextos como el español, el italiano o el irlandés y, de forma

3 Un elemento innovador de este trabajo es, sin duda, su metodología que hace hincapié en la necesidad de contextualizar los espacios de estudio e incluye una doble mirada, analizando contemporáneamente elementos de las sociedades de origen y destino.

4 Junto a Robert Park, como sostiene Ribas (2004, p. 25), otros precursores de la escuela fueron también Ernest Burgess y Roderick Mackenzie, mientras que, entre sus exponentes destacados, más allá de Louis Wirth, William Thomas y Florian Znaniecki, merecen ser enumerados también autores como Nels Anderson, Frederich Thrasher, Ruth Cavan o Clifford Shaw.

5 A título ilustrativo, de acuerdo con Giménez (2007), la influencia de exponentes de la antropología cultural como Franz Boas, Robert Redfield y Robert Lowie fue esencial para promover un mayor involucramiento de los exponentes de esta escuela en su contexto de estudio, mediante la observación participante y el trabajo de campo. 
creciente, pasó a privilegiar el análisis de los desplazamientos internacionales. Sin embargo, como destaca Giménez (2007), tanto los trabajos precursores de la Escuela de Chicago como los de la Escuela de Manchester y sus herederos se realizaron bajo la perspectiva del funcionalismo y la teoría de la modernización y, en menor medida, bajo la teoría de la dependencia. Así, solo el aumento de la complejidad de los flujos migratorios y la preferencia por su estudio a nivel global permitirían la adopción de nuevas teorías y el desarrollo de las premisas anunciadas por las primeras investigaciones.

La resignificación reciente de las relaciones sociales ante la compresión espaciotemporal (Harvey, 1989; Urry, 2007), propició el debate sobre la necesidad de adaptar la etnografia a las múltiples y heterogéneas interconexiones entre lo local y lo global. En efecto, las transformaciones provocadas por la globalización en las sociedades contemporáneas en ámbitos como la cultura, la política, la economía, las tecnologías del transporte e información aumentaron la movilidad humana y la interdependencia entre los países e hicieron cada vez más transnacionales tanto las prácticas de los sujetos como las de las instituciones y otros actores sociales.

Como mencionamos anteriormente, diversos autores habían intuido la necesidad de analizar las migraciones teniendo en cuenta los contextos de origen y recepción. No obstante, no es hasta la década de los noventa que la perspectiva transnacional cobra fuerza. Así, a la luz del trabajo de Linda Basch, Nina Glick Schiller y Cristina SzantonBlanc (1994, p. 7), el transnacionalismo define: "los procesos en los cuales los migrantes forjan y sostienen múltiples hilos de relaciones sociales que conectan a las sociedades de origen con las de destino". Desde este prisma, se contestan los análisis unidireccionales y asimilacionistas, mientras se subrayan las múltiples y sostenidas conexiones transfronterizas en la esfera económica, pero también política, social o cultural.

La teoría transnacional apoya su propuesta en la crítica al nacionalismo metodológico que permea todas las ciencias sociales y que acepta al Estado-nación y sus fronteras como elementos naturales e incuestionables, a la par que define a la sociedad nacional como la única unidad de investigación (Wimmer; Schiller, 2003). Por ello, aunque los Estados continúen siendo importantes, se estudian con atención nuevos agentes como los movimientos sociales y religiosos, las organizaciones del crimen organizado y los mismos migrantes que desarrollan múltiples prácticas y relaciones en "comunidades transnacionales" y "espacios transnacionales" (Faist, 2010) o en "campos sociales" Levitt y Schiller (2004).

En sintonía con estas propuestas surgen las etnografias multisituadas (Marcus, 2001), también llamadas multilocales o transnacionales, así como las etnografias globales (Burawoy, 2000), las topografias transnacionales (Besserer, 2004) o las etnografias desnacionalizadas (Amelina; Faist, 2012), cuyo objetivo es reformular la etnografia clásica para superar sus límites y adaptarla a los nuevos tiempos. Para Marcus (2001, p. 111), que publicó 
inicialmente su trabajo en $1995,{ }^{6}$ la etnografia multisituada en/del sistema mundo moderno: "[...] sale de los lugares y situaciones locales de la investigación etnográfica convencional al examinar la circulación de significados, objetos e identidades culturales en un tiempo-espacio difuso".

El carácter multilocal de este método ha sido cuestionado por Hannerz (2003, p. 206) debido a su significado "engañoso". 7 Para el autor, más que la suma de diversas unidades locales, lo que se construye con la metodología multisituada es un espacio translocal, formado por las relaciones que existen entre y dentro de los lugares que forman parte de una investigación. Es gracias al estudio de las conexiones y vínculos entre los sitios que la etnografia multisituada no es una mera comparación de unidades locales, si bien la posibilidad de contrastar diferencias y semejanzas entre los emplazamientos donde se lleva a cabo no es excluida. Precisamente, "la esencia de una investigación multisituada es seguir a las personas, conexiones, asociaciones y relaciones que atraviesan los espacios (porque ellos son sustancialmente continuos, pero espacialmente no contiguos) "(Falzon, 2009, p. 2).

Como método, la etnografia multisituada parte del supuesto que es cada vez más difícil circunscribir nuestros sujetos de estudio o fenómenos de análisis a las fronteras de un solo territorio. En un contexto altamente interdependiente no solo las personas son móviles, sino que las prácticas y las actividades llevadas a cabo por los sujetos y las instituciones son cada vez más transnacionales. Por esta razón, para investigar esta tipología de fenómenos, no es suficiente estar en nuestro espacio de estudio, conforme la concepción etnográfica clásica, sino que se vuelve necesario "estar ahí, ahí y también ahí" (Hannerz, 2003), o, en otros términos, "seguir" a nuestro fenómeno de investigación de forma itinerante (Marcus, 2001).

El recurso al análisis de situaciones en múltiples espacios no es un fenómeno nuevo, especialmente en lo que concierne la investigación de las migraciones, el estudio de los medios de comunicación, o las exploraciones sobre ciencia y tecnología. Sin embargo, la oficialización de la etnografía multisituada como práctica metodológica, es más bien reciente (Marcus, 2001; Hannerz, 2003; Falzon, 2009; Fitzgerald, 2006; Dumont, 2012; Fernández-Kelly, 2013). A nivel metodológico la etnografia multisituada o transnacional registra particularidades y no establece, por ejemplo, la estancia prolongada en el campo o la inmersión total en el mundo de los sujetos estudiados como requisitos para validar los datos del investigador (Marcus, 2001; Hannerz, 2003; Falzon, 2009; Dumont, 2012). Este método reconoce las dificultades para estudiar de forma exhaustiva un fenómeno de estudio móvil que involucra diversos territorios. Por ello, en su adopción para el estudio de las migraciones y otros fenómenos que involucran múltiples espacios, se ha

6 Con anterioridad a esta fecha existen algunos trabajos pioneros de Marcus que cuestionan la etnografia tradicional y que resalen a la segunda mitad de los años ochenta. Los mismos fueron elaborados junto a James Clifford y posteriormente en compañía de Michel Fischer (Dumont, 2012; Falzon, 2009).

7 Es la traducción literal del término misleading que puede también ser definido en castellano como erróneo, confuso, falaz o equívoco. 
consolidado el recurso a estancias cortas, entrevistas y otras técnicas, a expensas de la observación participante clásica (Hannerz, 2003).

A menudo, estos elementos han generado diversas "ansiedades metodológicas"8 (Marcus, 2001, p. 113) que acusan a la etnografia multilocal de falta de riqueza informativa, profundidad de análisis, o una menor atención hacia lo subalterno. Pero lo cierto es que diversas investigaciones (Fitzgerald, 2006; Sánchez, 2009; Pujadas, 2010; Hirai, 2012; Dumont, 2012; Fernández-Kelly, 2013; Restrepo, 2016) atestiguan que este método se ha afianzado en los últimos años como práctica predilecta para el estudio de las migraciones y otros fenómenos, así como para las actividades transnacionales a estos vinculados. En efecto, la etnografia transnacional permite el estudio de identidades colectivas, así como las prácticas transnacionales de migrantes - de manera individual o como diásporas - y Estados, en ámbito económico, pero también social, político, cultural o religioso (Fitzgerald, 2006; Hirai, 2012; Villarreal, 2016). Otras líneas de investigación particularmente proficuas son también los estudios longitudinales para entender procesos como la asimilación segmentada (Fernández-Kelly, 2013) o el estudio de las emociones relacionadas con los procesos migratorios y la diversidad de vivencias del fenómeno, según se trate de mujeres, refugiados, miembros del colectivo LGTBIQ, niños o personas con particulares adscripciones étnicas (Pujadas, 2010; Sánchez, 2009; Hirai, 2012; Restrepo, 2016).

\section{La etnografía hoy: retos, prácticas y oportunidades}

A partir de mediados del siglo xx podemos hablar de dos cambios fundamentales asociados al quehacer antropológico. Por una parte, se puede hablar de las transformaciones de las sociedades sobre las que los antropólogos hacían etnografía, a causa del exterminio físico, el etnocidio o de su conversión en naciones emergentes. Por otra, es preciso subrayar la modificación de la practica etnográfica, influenciada por el cambio de mirada que desde Occidente se tenía sobre esas "otras” sociedades (Boivin; Rosato; Arribas, 2004).

Así, como afirma Stavenhagen (1971), desde los sesenta, la antropología inició un profundo proceso de descolonización, permitiendo que sus marcos teóricos dominantes y los métodos asociados a su ejercicio experimentaran profundas revisiones. La etnografia no quedó al margen de estos debates y vivió una "crisis de autoridad y representación" (Clifford; Marcus, 1986) que desembocó en la modificación de sus bases y en la generación de nuevos modos de observar, describir y analizar, dentro y fuera del ámbito académico (Sánchez, 2009). No obstante, la etnografia se enriqueció con las críticas asumiendo nuevos retos y adaptándose a nuevos contextos y realidades heterogéneas, transnacionales y virtuales.

8 Los reproches hacia este método, desde luego, superan los tres elementos arriba mencionados e incluyen, por ejemplo, la debilidad de los vínculos que el investigador establece con sus interlocutores; la escasa reflexividad que existe en relación a la elección de los sitios o a las técnicas utilizadas; y el pretendido carácter holístico que de forma implícita o explícita asumen algunas investigaciones de este tipo (Hage, 2005; Candea, 2007 apud Falzon, 2009). 
Los cuestionamientos al método etnográfico envolvieron esferas como el etnocentrismo, la autoridad indiscutida de la escritura etnográfica (Clifford; Marcus, 1986) o la falta de una perspectiva de género (Behar; Gordon, 1995). Desde los años setenta, las condenas a la etnografia y los llamados a reformular algunos de sus postulados permitieron también la creación de códigos éticos profesionales, pues hasta entonces, diversas investigaciones dentro y fuera del ámbito académico, habían sido realizadas secretamente, en proyectos muchas veces vinculados a prácticas de espionaje o sin el explícito consentimiento de los sujetos de investigación (Sánchez, 2009, p. 45).

Como mencionamos en la introducción, tras la publicación del diario de Malinowski surgieron varias polémicas acerca de la diversidad de descripciones e interpretaciones según quien investiga - que junto a la emergencia de nuevas narrativas alteraron las, hasta entonces, formas clásicas de hacer etnografia. Este proceso fue paralelo a las dificultades prácticas del trabajo de campo de los antropólogos, sobre todo occidentales, tras los procesos de descolonización. Dichas dificultades surgieron como resultado de las críticas hacia las investigaciones antropológicas, así como por la disminución de fondos para investigaciones etnográficas prolongadas o por la proliferación de escuelas y tradiciones antropológicas en los países del Sur. Por otro lado, el giro marxista y, posteriormente, la asunción de nuevos enfoques posibilitó el repliegue de los antropólogos hacia sus realidades y las transformaciones que estas habían experimentado, enfocándose en fenómenos como la presencia de minorías étnicas, la migración internacional o los procesos de marginación en los países centrales (Pujadas, 2010). En otros términos, según Roberto da Matta (2004), de familiarizarse con lo exótico se pasó a exotizar lo familiar.

A raíz de las críticas a la tradición etnográfica positivista surge la etnografia posmoderna que tiende hacia el relativismo y aboga por una mayor reflexividad sobre el papel de los investigadores (Clifford; Marcus, 1986; Behar; Gordon, 1995; Guber, 2004). Esta etnografia emplea prácticas polifónicas y antiautoritarias que desestiman la objetividad de la etnografia clásica y consideran los resultados que de ella se derivan como textos escritos y construidos a partir de la subjetividad del etnógrafo y de sus formas de ver y entender el mundo (Pujadas, 2010, p. 57). Como corolario, se multiplican las nuevas formas de hacer etnografia que incorporan, por ejemplo, perspectivas desarrolladas previamente en el Sur (Krotz, 1993) y prácticas experimentales en las autoetnografias, así como etnografias aplicadas como las activistas y militantes (Denzin, 2003) o feministas y disidentes (Behar; Gordon, 1995). A su vez, influenciadas por perspectivas como la antropología de la acción (Sol Tax, 1937, apud Sánchez 2009) o enfoques interdisciplinares, estas se combinan con prácticas que llaman la atención sobre la necesidad de dar mayor protagonismo a los sujetos de la investigación o de considerar con más énfasis sus especificidades, dando lugar a las etnografias participativas y comunitarias. Aquí como en otros debates que enriquecieron la teoría y la práctica etnográfica, la aportación de autores latinoamericanos, africanos y asiáticos fue fundamental.

Por otro lado, de acuerdo a las informaciones expuestas en el acápite anterior, la etnografia como método descriptivo y reflexivo, utilizado sobre todo por los antropólogos 
sociales, se desarrolló a partir de diversas disciplinas, entre las que destacan la sociología y la psicología social, esta última vinculada a la introducción de procedimientos experimentales. En este sentido, al contrario de las creencias sociales más arraigadas, la etnografía es un método interdisciplinar.Además, a pesar de estar asociada con la antropología, el paradigma cualitativo y especialmente con la observación participante, la etnografia es un método multitécnico en el que la observación participante ocupa un lugar protagonista, pero no único (Hammersely; Atkinson, 1994; Mora, 2010; Apud, 2013). La etnografia tiene, en efecto, un carácter flexible y abierto y, en sintonía con los fines de la investigación propuesta o del escenario en el que se desarrolla, puede o debe emplear la observación participante con información proveniente de fuentes plurales como entrevistas, censos, surveys, mapas, datos estadísticos y demográficos o documentos audiovisuales. De esta forma, según Mora (2010), existirían diversos estilos etnográficos.

Por su parte, procesos como la globalización o la difusión de las Tecnologías de la Información y Comunicación (TICs) han permitido la emergencia de nuevas formas de hacer y pensar las etnografias. Este nuevo contexto implica cuestionarse la manera en que ha cambiado la observación participante y el trabajo de campo etnográfico como también discurrir que esto es una consecuencia de los cambios en las circunstancias tanto en el mundo "real" como en el "virtual" (Angrosino, 2012). No solo ha cambiado el qué investigar, asociado al objeto de estudio, sino el cómo investigar, relacionado con las herramientas con las que contamos los y las etnógrafas para hacer investigación.

Con todo, a través de la difusión del uso de las TICs, existe cada vez más interacción y es posible mantener o profundizar los lazos entre personas y comunidades, así como desarrollar nuevas y diferenciadas identidades. En efecto, de forma creciente - a título individual o colectivo - se comparten pensamientos, gustos y otras informaciones sobre sí mismos o sobre el grupo de referencia en plataformas online y redes sociales. Por otro lado, migrantes individuales o autoidentificados como parte de una diáspora, así como personas con variadas características pueden crear nuevos espacios de interacción en torno a intereses comunes de carácter político, étnico, económico, religioso o cultural (Sánchez, 2009, p. 44). En este contexto, la netnografia, también denominada etnografia en línea, virtual, etnografia online o ciberantropología (Kozinets, 1997; Markham, 2005; Hine, 2000;Vásquez, 2008, apud Del Fresno, 2011, p. 59) o etnografia del ciberespacio y de la cibercultura9 (Restrepo, 2016), constituye una adaptación de la etnografia a los nuevos tiempos y formas de interacción en el ciberespacio que permite estudiar comunidades virtuales, anteriormente desconocidas, o profundizar el estudio de las analizadas mediante el método clásico.

Las comunidades virtuales, transnacionales o no, se caracterizan por la comunicación mediada por dispositivos electrónicos como computadores o smartphones y las interacciones en línea, en vez de por la proximidad geográfica o los lazos de parentesco (Angrosino,

9 Para Escobar (2005), la cibercultura se refiere específicamente a nuevas tecnologías en dos áreas: (a) Inteligencia artificial, particularmente tecnologías de computación e información; y (b) la biotecnología. Para el autor, es posible separar estos dos conjuntos de tecnologías para propósitos analíticos; sin embargo, no es una coincidencia que los dos hayan alcanzado su actual auge de manera simultánea. 
2012). El ciberespacio es el ámbito sobre el que se realiza el trabajo de campo en las etnografias virtuales (Restrepo, 2016). Por lo tanto, la etnografia de la cibercultura estudia el modo en el que las personas se comportan e interactúan en el mundo digital. Sin embargo, no se limita simplemente a una etnografia online. En este sentido, Internet es entendido como un espacio socio-cultural y, por lo tanto, los datos producidos en las redes son entendidos como contenido cultural (Reyero, 2017). Consecuentemente, es importante que concibamos los productos que se generan a partir de la interacción de las personas con las TICs como productos culturales, por lo que pueden ser objeto de investigación etnográfica. Así, este tipo de etnografias estudian cómo se construyen prácticas, subjetividades y relaciones sociales en el ciberespacio (Restrepo, 2016). Pero, esto implica que debemos transformar la etnografia convencional para que se ajuste a los retos y especificadas del ciberespacio.

La etnografia digital comparte con la etnografía clásica su carácter interdisciplinar y multitécnico con la combinación de observación participante y no participante junto a entrevistas, análisis de contenido, encuestas, grupos focales o análisis de redes sociales (Del Fresno, 2011). Paralelamente, disminuye la influencia del observador, pues permite acceder desde diversos ámbitos - incluido el hogar o lugar de trabajo - a comunidades de imposible o dificil contacto no virtual, a la par que posibilita profundizar el estudio de comunidades estudiadas de manera presencial y analizar de manera eficiente y simultánea grandes cantidades de informaciones altamente volátiles que, gracias a la geocalización, permiten la inclusión de detalles sobre ámbitos como la ubicación geográfica de los sujetos. Estas posibilidades aumentan si se recurre a softwares especializados para el análisis de datos cualitativos y cuantitativos. No obstante, presenta menos riqueza informativa respecto a la etnografia clásica y priva el método de su técnica protagonista: la observación participante y la interacción directa con los sujetos. Supone también diversos desafios a la hora de seleccionar muestras de comunidades activas y abiertas, con especificidades en el uso del lenguaje o en las formas de interacción. Además, un aspecto no menos relevante es la necesidad de estar guiados por presupuestos éticos y normas en relación a la permisividad para realizar la investigación (Del Fresno, 2011), así como respecto a la privacidad de los datos y las personas o el respeto de sus reglas de admisión y participación (Angrosino, 2012).

Con todo, el uso de las nuevas tecnologías en la práctica etnográfica es al mismo tiempo fuente de nuevas posibilidades y de diversas discusiones sobre las maneras más o menos indicadas de utilizarlas. A causa de la sofisticación tecnológica, las y los actuales etnógrafos pueden tomar notas, grabar audio, registrar imágenes y video con un único dispositivo, usando programas o plataformas como Endnote o ETHNOKEN ${ }^{10}$, que están desplazando parcialmente el cuaderno y el bolígrafo. Como consecuencia, con la aparición de los computadores portátiles, los smartphones, las tabletas y los programas informáticos para el análisis de datos, la toma de notas se ha transformado.

10 Sistema de anotación y almacenamiento en línea, para compartir datos etnográficos y construir conversaciones mientras están en el campo. 
Es común, por ejemplo, que los alumnos de los actuales cursos de ciencias sociales afirmen tomar notas de campo directamente desde sus dispositivos móviles y que, muchas veces, les parezca extraño el uso de otras prácticas o la realización de etnografias en contextos adversos sin energía eléctrica o acceso a internet. A este respecto, es importante señalar que, aunque desde la academia no se ha consensuado una única forma de hacer notas de campo, no se cuestiona el papel central que estas ocupan en la etnografia. Recordemos que, como bien señaló Geertz (1973), el trabajo de campo etnográfico no sólo se limita a la observación participante, sino que implica la elaboración de una "descripción densa", producto justamente de la interpretación de las observaciones que el etnógrafo hace a través de las notas de campo. La interconexión entre la observación participante, la elaboración de las notas y la interpretación de las mismas son el núcleo de la investigación etnográfica (Emerson; Fretz; Shaw, 1995). Como asevera Taussig (2015), es justamente a través del proceso de escribir las notas de campo que los y las etnógrafas comenzamos a desarrollar datos e interpretaciones que trascienden la observación (Cury, 2015).

El uso de dispositivos como los smartphones hace que los y las etnógrafas registremos nuestros datos de una manera diferente. La forma en que pensamos, hablamos y generamos notas de campo nos da credibilidad (Cury, 2015). Sin embrago, el uso de "live fieldnotes" compartidos con una audiencia más amplia como fragmentos instantáneos del campo a través de plataformas de redes sociales (Cury, 2015; Reyero, 2017) abre también nuevos caminos.

Asimismo, el uso de terminales ha promovido el desarrollo de aplicaciones para realizar investigación cualitativa digitalmente que, además de servir para el registro de notas, imágenes y audios, están diseñadas para permitir el diálogo entre investigadores y sujetos de investigación (Reyero, 2017). Algunas de estas aplicaciones son: Ethos, una plataforma que pone el énfasis en la instantaneidad de los datos y la emotividad de las situaciones registradas en tiempo real ${ }^{11}$; o también está Overtheshpulder ${ }^{12}$, que facilita la comparación y categorización de datos, presentándolo todo en interfaces digitales; o Podio, un software de gestión de proyectos online.

Aunque estas aplicaciones han sido desarrolladas sobre todo en el ámbito de la antropología del mercado, se convierten en herramientas interesantes para trabajar desde la perspectiva de la antropología activista o colaborativa, pues los sujetos de investigación pueden registrar datos, tomar fotos o videos y enviar información en tiempo real. Rappaport (2007, p. 197), quien ha trabajado desde la etnografia en colaboración con investigadores indígenas en Colombia, pero no necesariamente con la mediación de TICs, sugiere que la etnografia es un espacio crítico en el cual antropólogos e interlocutores participan conjuntamente en la co-teorización, lo que implica la posibilidad de aportar nuevas perspectivas a la disciplina.

11 https://www.ethosapp.com/

12 www.overtheshoulder.com/ 
Desde esta óptica se aboga por una mayor colaboración en la práctica etnográfica y en el intercambio de conocimientos entre los investigadores y los sujetos de investigación que permite la implicación de estos últimos en el proceso de investigación. Aquí las plataformas son útiles, pues podrían generar un espacio horizontal en la construcción de los datos de campo, ya que los interlocutores registran aspectos de sus vidas y los suben a las plataformas, eliminando así el monopolio sobre los datos que mantenía el etnógrafo. De esta forma, por ejemplo, durante el trabajo de campo de una de las autoras de este artículo (Calle, 2015), esta invitó a sus interlocutores a que dialogaran sobre sus notas de campo. Desde nuestro punto de vista, este tipo de ejercicio no rompe del todo con la relación asimétrica entre el sujeto investigador y el sujeto de estudio, pero sí se aproxima a la construcción de datos desde una perspectiva crítica y colectiva donde la voz de los interlocutores hace parte del análisis (Ramírez, 2010; Calle, 2015); muy diferente a un proceso de investigación en el que el investigador se limita a observar y participar, sin involucrar a los sujetos de investigación en sus análisis (Rabinow et al., 2008; Ramírez, 2010; Calle, 2015).

En el caso de la posibilidad de acceso a internet, las formas de interacción se multiplican, facilitando procesos de comunicación posteriores al trabajo de campo, realización de etnografias transnacionales con mayores y más heterogéneos datos y procesos de colaboración. Así, por ejemplo, algunos etnógrafos en línea han adoptado la práctica de compartir el borrador del informe de investigación para su comentario por los miembros de la comunidad virtual. Para Angrosino (2012), cuando el investigador permite que los sujetos de investigación decidan sobre los contenidos y la manera en que van a ser utilizados sus comentarios, "[...] se logra la meta ética superior de convertir a los "sujetos" en "colaboradores" verdaderamente empoderados [...]” (Angrosino, 2012, p. 128).

\section{Reflexiones finales}

Tanto en los estudios migratorios como en otros ámbitos de investigación, la etnografía constituye un método reflexivo y de gran utilidad para comprender las particularidades de un determinado fenómeno o grupo de investigación, así como para el desarrollo teórico o para contrastar hipótesis. Concebida como método, texto o proceso, la etnografía se presenta como un recurso flexible y abierto, cuyas estrategias y orientaciones pueden cambiar fácilmente brindando, en consecuencia, amplias posibilidades tanto al aprendizaje como a la creatividad de los investigadores. Cuestionada y autocriticada por sus orígenes occidentales, promoción de prácticas etnocéntricas o por no considerar debidamente las diferencias de género o los puntos de vista de los sujetos investigados, a lo largo del tiempo ha sobrevivido superando sus límites, adaptándose a nuevas circunstancias y manteniéndose como un importante recurso para la investigación en ciencias sociales. Por otro lado, desde el momento en el que la etnografia pasa a ser practicada también por investigadores de América Latina y otras regiones, se han enriquecido las formas tradicionales de realizarla, han 
surgido las etnografias desnacionalizadas, participativas, feministas, comunitarias, activistas o disidentes y, con ello, se han multiplicado también sus desafios.

Si bien en cuanto estrategia o forma de investigar, la etnografia nace en el seno de la antropología social, como vimos a lo largo de este texto, desde sus orígenes se ha nutrido de la aportación de otras disciplinas. Los trabajos realizados por la Escuela de Sociología de Chicago sobre migraciones, minorías y procesos de exclusión fueron, por ejemplo, esenciales para su desarrollo, mientras que las contribuciones de otros campos hacen de ella un método esencialmente interdisciplinar. Otro rasgo fundamental de la etnografia es su multitecnicidad y su carácter abierto a la experimentación, lo que permite combinar en un mismo proceso observación participante y entrevistas, pero también recursos audiovisuales, fuentes estadísticas, historias de vida o documentos de archivo.

A partir de sus características, en diversos campos, pero particularmente en los estudios migratorios, la etnografia ha evolucionado desde las descripciones densas sobre el terreno, realizadas por largos periodos y concentradas en un único espacio, a las etnografias multisituadas o transnacionales que consideran las múltiples interacciones y lazos que los migrantes mantienen con diversos destinos. A menudo, la realización de este tipo de etnografias modifica los principios del método tradicional al no requerir, por ejemplo, la permanencia del investigador en el campo por largos periodos, sino más bien su desplazamiento continuo con el fin de "seguir" a sus sujetos y fenómenos de investigación. Esta adaptación de la etnografía a nuevos tiempos caracterizados por la globalización, la reducción de distancias y la mayor interdependencia entre sociedades, no ha soslayado el desarrollo y difusión de las TICs. En efecto, de la mano de las nuevas y heterogéneas formas de interacción o del establecimiento de comunidades virtuales, surgió la etnografía virtual que, según la perspectiva adoptada, puede asumir otras nomenclaturas como etnografia digital o etnografía del ciberespacio.

Si tuviésemos que pensar en un ejemplo concreto, en el campo de las migraciones la riqueza de la etnografía es tal que, hoy en día, a partir de un cyber café o cabina telefónica podríamos realizar una etnografía tradicional, al tiempo que desarrollamos una etnografía multisituada, siguiendo a nuestros sujetos de investigación y sus conexiones con sus países de origen. Paralelamente, podríamos hacer una etnografía virtual para comprender las prácticas mediante las cuales los migrantes perpetúan o difunden su cultura, o a través de las cuales participan activamente de sus comunidades de origen y residencia a nivel económico, político o religioso. Con estas transformaciones y la multiplicación de posibilidades surgen, sin embargo, nuevos retos que tienen que ver con no descaracterizar el método etnográfico a partir de estancias express en nombre de la eficiencia o mediante análisis superficiales de un determinado colectivo. En la misma medida, es menester prevenir la sustitución del análisis e interpretación del etnógrafo por softwares para el manejo de datos etnográficos. En efecto, el principal reto consiste en evitar que, a pesar de su importancia y facilitación del análisis, la herramienta digital no se convierta en el método como tal y, por ende, que la tecnología no defina o sustituya a la etnografia, sino que se mantenga como una herramienta de investigación. 


\section{Bibliografía}

AGAR, Michael. The Professional Stranger: An Informal Introduction to Etnography. San Diego: Academic Press, 1980.

AMELINA, Anna; FAIST, Thomas. De-naturalizing the national in research methodologies: key concepts of transnational studies of migration, Ethnic and Racial Studies, v. 35, n. 10, p. 1707-1724, 2012. ANGROSINO, Michael. Etnografía y observación participante en Investigación Cualitativa. Madrid: Ediciones Morata; Colección: Investigación Cualitativa, 2012.

APUD, Ismael. Repensar el método etnográfico. Hacia una etnografía multitécnica, reflexiva y abierta al diálogo interdisciplinario. Antípoda. Revista de Antropología y Arqueología, n. 16, p. 213-135, 2013.

ASAD, Talal, Anthropology and the Colonial Encounter. In: HUIZER, Gerry; MANHEIM, Bruce (Ed.). The Politics of Anthropology: From Colonialism and Sexism Toward a view from Below. The Hague Mouton, 1979.

BASCH, Linda; GLICK SCHILLER, Nina; SZANTON BLANC, Cristina. Nations Unbound:Transnational Projects, Postcolonial Predicaments and Deterritorialized Nation-States. London: Routledge, 1994.

BEHAR, Ruth; GORDON, Deborah. Women Writing Culture. Berkeley: University of California Press, 1995.

BESSERER, Federico. Topografías transnacionales: hacia una geografia de la vida transnacional. Universidad Autónoma Metropolitana. México, DF: Plaza y Valdés Editores, 2004.

BOIVIN, Mauricio; ROSATO, Ana; ARRIBAS, Victoria. Introducción. In: BOIVIN, Mauricio; ROSATO, Ana; ARRIBAS, Victoria. Constructores de Otredad: una introducción a la antropología social y cultural. Buenos Aires: Antropofagia, 2004.

BURAWOY, Michael. Global Ethnography: Forces, Connections and Imaginations in a Postmodern World. Berkeley: University of California Press, 2000.

CALLE, Laura. La Insaciable Búsqueda de El Dorado: Procesos Hegemónicos y Dispositivos de Dominación en un Pueblo Sikuani de la Orinoquía Colombiana. Madrid, 2015. Tesis (Doctorado en Antropología) - Universidad Complutense de Madrid.

CLIFFORD, James. On ethnographic Self-Fashioning: Conrad and Malinowski. In: THOMAS, Heller; WELLBERY, David; SOSNA, Morton (Ed.). Reconstructing Individualism: Autonomy, Individuality, and the Self in Western Thought, Stanford: Stanford University Press, 1985.

Dilemas de la cultura. Antropología, literatura y arte en la perspectiva posmoderna. Barcelona, Gedisa Editorial, 2001.

; MARCUS, George (Ed.). Writing Ethnography: The Poetics and Politics of Ethnography. Berkeley: University of California Press, 1986.

CURY, Maria. Field notes as a social practice. Elevating and Innovating fieldnotes in applied ethnography, using a collaborative online tool as a case study. 2015. Disponível em: $<$ http://www.redassociates.com/perspectivesposts/2015/11/13/fieldnotes-as-s-social-practice>. Acesso em: 15 jun. 2017.

DA MATTA, Roberto. El oficio del etnólogo o cómo tener “Anthropological Blues”. In: BOIVIN, Mauricio; ROSATO, Ana;ARRIBAS,Victoria. Constructores de Otredad: una introducción a la antropología social y cultural. Buenos Aires: Antropofagia, 2004.

DEL FRESNO, Miguel. Netnografía. Barcelona: Editorial UOC, 2011.

DENZIN, Norman. The call to perfomance. Symbolic Interaction, v. 26, n. 1, p. 187-207, 2003.

DUMONT, Guillaume. Multiplicidades móviles, dibujo de una pluralidad situacional, Encrucijadas. Revista Crítica de Ciencias Sociales, n. 4, p. 66-80, 2012.

EMERSON, Robert; FRETZ, Rachel; SHAW, Linda. Writing Ethnographic Fieldnotes. Chicago: University of Chicago Press, 1995. 
ESCOBAR, Arturo. Bienvenidos a Cyberia. Notas para una antropología de la cibercultura. Revista de Estudios Sociales, p. 15-35, 2005.

EVENS, Terry; HANDELMAN, Don. Introduction:The Ethnographic Praxis of Theory of Practice. In: EVENS, Terry; HANDELMAN, Don (Ed.). The Manchester School: practice and ethnographic praxis in anthropology. New York: Berghahn Books, 2006.

FAIST, Thomas. Diaspora and Transnationalism: What kind of dance partners. In: BAUBÖCK, Rainer; FAIST, Thomas (Ed.). Diaspora and Transnationalism. Concepts, Theories and Methods. Amsterdam: Amsterdam University Press, 2010.

FALZON, Mark-Anthony. Introduction: Multi-sited Ethnography: theory, praxis and locality in contemporary research. In: FALZON, Mark-Anthony (Ed.) Multi-sited Ethnography: theory, praxis and locality in contemporary research. Surrey: Ashgate, 2009.

FERNÁNDEZ-KELLY, Patricia. Making sense of the other: ethnographic methods and immigration research. In: GOLD, Steven; NAWYN, Stephanie (Ed.). The Routledge International Handbook of Migration Studies. London \& New York: Routledge, 2013.

FITZGERALD, David. Towards a Theoretical Ethnography of Migration. Qualitative Sociology, v. 29, n. 1, p. 1-24, 2006.

GIMÉNEZ, Carlos. Migración, sociedad y cultura. La perspectiva antropológica. In: LISÓN, Carmelo (Coord.). Introducción a la antropología social y cultural: teoría, método y práctica. Madrid: Akal, 2007.

GEERTZ, Clifford. The Interpretation of Cultures. New York: Basic Books, 1973.

El antropólogo como autor. Barcelona: Paidós, 1989.

GUBER, Rosana. La Etnografía: Método, campo y reflexividad. Bogotá: Norma, 2001.

El salvaje metropolitano: reconstrucción del conocimiento antropológico en el trabajo de campo. Buenos Aires, Barcelona, México: Paidós, 2004.

.La Etnografía: método, campo y reflexividad. Buenos Aires: Siglo XXI, 2011.

HAMMERSLEY, Martyn; ATKINSON, Paul. Etnografía: métodos de investigación. Barcelona: Paidós, 1994.

HANNERZ, Ulf. Being there... and there... and there! Reflections on Multi-Site Ethnography, Ethnography, v. 4, n. 2, p. 201-216, 2003.

HARVEY, David. The condition of postmodernity: an inquiry into the origins of cultural change. Cambridge: Blackwell Publishers, 1989.

HIRAI, Shinji. ¡Sigue los símbolos del terruño!”: etnografía multilocal y migración transnacional. In: ARIZA Marina;VELASCO, Laura (Coord.) Métodos Cualitativos y su aplicación empírica: por los caminos de la investigación sobre migración internacional. México: UNAM, Instituto de Investigaciones Sociales; El Colegio de la Frontera Norte, A.C., 2012.

KOTTAK, Conrad. Antropología Cultural. México: McGraw Hill, 2011.

KROTZ, Esteban. La producción de la antropología en el Sur: características, perspectivas e interrogantes. Alteridades, v. 3, n. 6, p.5-11, 1993.

KUPER, Adam. Anthropology and Athropologists: The Modern British School 1922-1972. New York: Pica Press, 1973.

LEDERMAN, Rena. Pretexts for Ethnography: On Reading Fieldnotes. In: SANJEK, Roger (Ed.). Fieldnotes: The Makings of Anthropology. Ithaca and London: Cornell University, 1990.

LEVITT, Peggy; SCHILLER, Nina. Perspectivas Internacionales sobre migración: conceptuar la simultaneidad. Migración y Desarrollo, n. 3, p. 60-91, 2004.

MALINOWSKI, Bronisław. [1922]. Los argonautas del Pacífico occidental: Comercio y aventura entre los indígenas de la Nueva Guinea melanésica. Barcelona: Ediciones Península, 2001. 
MARCUS, George; CUSHMAN, Dick. Ethnographies as Texts. Annual Review of Anthropology, v. 11, p. 25-69, 1982.

MARCUS, George. Etnografia en/del sistema mundo. El surgimiento de la etnografia multilocal, Alteridades, v. 11, n. 22, p. 111-127, 2001. Disponible en: < http://www.redalyc.org/pdf/747/74702209.pdf>. Acceso: 01 dec. 2017.

MORA, Héctor. El método etnográfico: origen y fundamentos de una aproximación multitécnica. Forum Qualitative Social Research, v. 11, n. 2, 2010. Disponible en: <www.qualitative-research.net/index.php/fqs/article/ download/1283/2957>. Acceso en: 24 jun. 2017.

MORTON, Sosna; WELLBERY, David. (Ed.) Reconstructing individualism: autonomy, individuality, and the self in Western thought. Stanford: Stanford University Press, 1985.

NASH, June. Nationalism and Fieldwork. Annual Review of Anthropology, vol. 4, p. 225-245, 1975. doi: https://doi.org/10.1146/annurev.an.04.100175.001301

ORTNER, Sherry. Theory in Anthropology Since the Sixties. Comparative Studies in Society and History, v. 26, n. 1, p. 126-166, 1984.

PUJADAS, Joan. La etnografia como mirada a la diversidad social y cultural. In: PUJADAS, Joan; COMAS D’AR GERMIR, Dolors; ROCA I GIRONA, Jordi. Etnografía. Barcelona: Editorial UOC, 2010.

RABINOW, Paul; MARCUS, George; FAUBION, James; REES, Tobias. Designs for an Anthropology of the Contemporary. Durham and London: Duke University Press, 2008.

RAMÍREZ, María. Un recorrido conceptual por algunos de los nuevos ejes de estudio de la Antropología: el estado, la política pública y la corrupción. In: CICLO DE CONFERENCIAS DE LA MAESTRÍA EN ANTROPOLOGÍA. PERSPECTIVAS ANTROPOLÓGICAS E INVESTIGACIÓN SOCIAL, VI, 2010, Bogotá. Anais... Bogotá: Universidad Nacional de Colombia, 2010.

RAPPAPORT, Joanne. Más allá de la escritura: La epistemología de la etnografía en colaboración. Revista Colombiana de Antropología, v. 43, p. 197-229, 2007.

RESTREPO, Eduardo. Etnografía: alcances, técnicas y éticas. Bogotá: Envión Editores, 2016.

REYERO, Verónica. Smartphone ethnography. Aplicaciones móviles para hacer etnografía.Antropología 2.0. Disponible en: <http://antropologia2-0.com/es/aplicaciones-moviles-etnografia/>.Acceso en: 15 jun. 2017.

RIBAS, Natalia. Una invitación a la sociología de las migraciones, Barcelona: Bellaterra, 2004.

RICHARDS, Audrey Isabel, Land, Labour and Diet in Northern Rhodesia: and economic study of the Bemba tribe. Oxford: Oxford University Press, 1939.

SÁNCHEZ, Raúl. La etnografía y sus aplicaciones: Lecturas desde la antropología social y cultural. Madrid: Editorial Universitaria Ramón Areces, 2009.

STAVENHAGEN, Rodolfo. Decolonializing Applied Social Sciences. Human Organization, v. 30, n. 4, p. 333-344, 1971. doi: https://doi.org/10.17730/humo.30.4.p1w7700v333n6871

TAUSSIG, Michael. Excelente Zona Social. In: ORIN, Starn (Ed.). Writing Culture and The Life of Anthropology. Durham and London: Duke University, 2015.

THOMAS, William; ZNANIECKI, Florian. The Polish Peasant in Europe and America. Chicago: University of Chicago Press and Boston: Gorham Press, 1918-1920.

URRY, John. Mobilities. Cambridge: Polity Press. 2007.

URRY, James. A history of field methods. In: ROY, F. Ellen (Ed.). Ethnographic Research: a Guide to General Conduct. London: Academic Press, 1984. p. 35-61.

VILLARREAL, María, Migraciones, desarrollo y políticas migratorias: análisis de la experiencia ecuatoriana. 2016. Tesis (Doctorado en Ciencia Política) - Universidad Complutense de Madrid, Madri, 2016. 
WEBER, Max [1922]. Economía y sociedad: Esbozo de sociología comprensiva. Madrid: Fondo de Cultura Económica, 2002.

WIMMER, Andreas; SCHILLER, Nina. Methodological Nationalism, The Social Sciences and the study of migration: An Essay in Historical Epistemology. International Migration Review, v. 37, n. 3, p. 576-610, 2003.

WIRTH, Louis [1928]. The Guetto. New Brunswick and London:Transaction Publishers, 1997. 


\title{
Etnografia dentro e fora dos estudos migratórios: uma revisão relevante
}

\section{Resumo}

Este artigo visa dar conta dos usos, desafios e oportunidades oferecidas pela etnografia nos estudos migratórios e outros campos de pesquisa. Com este fim, ofereceremos, em primeiro lugar, um breve resumo sobre a história do trabalho de campo etnográfico e uma descrição e análise da etnografia como método, texto e enfoque. A seguir, nos debruçaremos na análise da etnografia nos estudos migratórios, partindo das etnografias clássicas até o desenvolvimento das etnografias multisituadas. Finalmente, analisaremos a diversidade de campos de aplicação da etnografia e suas raízes interdisciplinares e multitécnicas. Por sua vez, de acordo com as mudanças propiciadas pela globalização e a difusão das novas Tecnologias da Informação e Comunicação (TICs), abordaremos também as potencialidades e limites da etnografia da cibercultura ou etnografia digital.

Palavras-chave: Etnografia, migrações internacionais, diásporas, etnografia digital.

\section{Ethnography inside and outside migratory studies: a relevant review}

\begin{abstract}
This article aims to explain the uses, challenges and opportunities offered by ethnography in migratory studies and other fields of research. For this purpose, we will first offer a summary on the history of ethnographic field work and a description and analysis of ethnography as method, text, and approach. Next, we will focus on the analysis of ethnography in migratory studies, starting with the classical ethnographies up to the development of multi-sited ethnographies. Finally, we will approach the diversity of the fields of application of ethnography and of its interdisciplinary and multi-technical origins. Afterwards, in line with the changes brought by globalization and the diffusion of new Information and Communication Technologies (ICTs) we will also analyze the potentialities and limits of the ethnography of cyberculture or digital ethnography.
\end{abstract}

Keywords: Ethnography, international migrations, diasporas, digital ethnography.

Data de recebimento do artigo: 24/07/2017

Data de aprovação do artigo: 14/09/2017 